\title{
Estrategias pragmático-discursivas en escritos de calificación provisional y defensa en juicio oral
}

\author{
ÁNGEL CERVERA RODRÍGUEZ** \\ JOSÉ TORRES ÁLVAREZ****
}

Recepción: 15 de diciembre de 2017

Aprobación: 26 de abril de 2018

Forma de citar este artículo: Cervera, A. \& Torres, J. (2018). Estrategias pragmático-discursivas en escritos de calificación provisional y defensa en juicio oral. Cuadernos de Lingüística Hispánica, (32), 87-105.

* Artículo de investigación de tipo empírico y de carácter etnometodológico, perteneciente al grupo "Lingüística aplicada al análisis del discurso oral y escrito en español”, y al proyecto de Referencia: PR26/26-20258, subvencionado por la Universidad Complutense de Madrid y el B. de Santander.

** El autor es doctor en Filología por la UCM y profesor titular en el Departamento de Lengua Española, Teoría de la Literatura y Literatura Comparada, Facultad de Filología, Universidad Complutense de Madrid. (España). Sus líneas de investigación son, principalmente, gramática, semántica, pragmática y análisis del discurso en español. Correo electrónico: cervera1@ucm.es

*** El autor es doctor en Lengua Española y sus Literaturas por la UCM, ha sido profesor del módulo de Español para Fines Específicos International Business and Spanish en la Aston University (Birmingham) y actualmente es profesor en la Generalitat de Catalunya (España). Sus líneas de investigación son gramática, pragmática y análisis del discurso en español. Es investigador colaborador del grupo de investigación de Lingüística Aplicada en el Departamento de Lengua Española. Correo electrónico: torresalj@gmail. com 


\title{
Resumen
}

Esta investigación tiene como objetivo explicar el funcionamiento de las estrategias pragmáticas y dialécticas en el discurso forense, además de describir la interacción comunicativa entre la parte acusada y la acusadora, para determinar qué estrategias lingüístico-pragmáticas utilizan los abogados de la acusación y de la defensa a fin de convencer al juez de que avale la culpabilidad o inocencia del acusado. El corpus está formado por el escrito de conclusiones de calificación provisional y defensa en un juicio oral celebrado en los juzgados penales de Barcelona en 2010. Para conseguir este objetivo, se ha procedido a identificar los componentes lingüísticos y los indicadores dialéctico-argumentativos a los que recurren las partes en sus intervenciones, siguiendo una metodológica basada en la teoría pragmadialéctica, la etnometodología, la argumentación y la (des)cortesía. Entre los resultados destacan la nominalización, la recurrencia léxica y gramatical y los indicadores deícticos personales y operadores discursivos. A estas estrategias se unen las derivadas de la imagen que proyecta cada parte donde entra el juego de la cortesía o la descortesía.

Palabras clave: lingüística, discurso forense, pragmática, dialéctica y argumentación.

\section{Pragmatic-Discursive Strategies in Writings of Provisional Qualification and Defense in Oral Trial}

\begin{abstract}
The purpose of this research is to explain how pragmatic and dialectical strategies works in forensic discourse and to describe the communicative interaction between the prosecution and the defense in order to determine how the prosecution and the defense use these strategies to persuade the judge about the innocence or the culpability of the accused. The corpus is based on the first statements provided by the prosecution and the defense during an oral trial held in the Criminal Courts of Barcelona in 2010. To achieve this objective, we have proceeded to identify the linguistic components and the dialectical-argumentative indicators that the parties use in their interventions, following a methodology based on pragma-dialectic theory, ethnomethodology, argumentation and (dis) courtesy. Among the results, the nominalization, the lexical and grammatical recurrence and the personal deictic indicators and discursive operators stand out. These strategies are joined by those that derive from the image projected by each part where courtesy or discourtesy comes into play.
\end{abstract}

Keywords: linguistics, forensic speech, pragmatics, dialectic and argumentation. 


\section{Stratégies pragmatique-discursives dans des écrits de qualification provisoire et défense dans un jugement oral}

\section{Résumé}

Cette recherche a comme objectif, expliquer le fonctionnement des stratégies pragmatiques et dialectiques dans le discours légiste, en plus de décrire l'interaction communicative entre la partie accusée et celui qui accuse. Ceci pour déterminer quelles stratégies linguistique-pragmatiques utilisent les avocats de l'accusation et de la défense, à fin de convaincre le juge du fait de valider la culpabilité ou l'innocence de l'accusé. Le corpus est formé par l'écrit des conclusions de qualification provisoire et défense dans un jugement oral célébré dans les tribunaux pénaux de Barcelone en 2010. Pour y arriver, on a procédé à identifier les composants linguistiques et les indicateurs dialecte-argumentatifs auxquels les parties font appel dans leurs interventions, en suivant une méthodologie basée sur la théorie pragma-dialectique, l'ethnométhodologie, l'argumentation et la (im)politesse. Dans les résultats, on met en évidence la nominalisation, la récurrence lexicale et grammaticale, et les indicateurs d'interprétation personnels et des opérateurs discursifs. On joint à ces stratégies, les dérivées de l'image que chaque partie projette, où on trouve le jeu de la courtoisie ou du manque de celle-ci.

Mots clés: linguistique, discours légiste, pragmatique, dialectique et argumentation.

\section{Estratégias discursivas pragmáticas em escrituras de classificação provisória e de defesa no julgamento oral}

\section{Resumo}

0 objetivo desta pesquisa é explicar o funcionamento de estratégias pragmáticas e dialéticas no discurso forense, além de descrever a interação comunicativa entre 0 acusado e 0 acusador, a fim de determinar quais estratégias linguístico-pragmáticas são utilizadas pelos promotores e advogados de defesa. a fim de convencer o juiz a defender a culpa ou inocência do acusado. 0 corpus consiste no resumo das conclusões da qualificação provisória e da defesa em um julgamento oral realizado nas cortes criminais de Barcelona em 2010. Para alcançar este objetivo, procedeu-se à identificação dos componentes linguísticos e dos indicadores dialético-argumentativos aos quais as partes recorrem às suas intervenções, seguindo uma abordagem metodológica baseada na teoria pragma-dialética, etnometodologia, argumentação e (des) cortesia. Os resultados incluem nominalização, recorrência lexical e gramatical e indicadores dêiticos pessoais e operadores discursivos. Estas estratégias são unidas pelos derivados da imagem projetada por cada parte onde 0 jogo de cortesia ou descortesia entra em jogo.

Palavras-chave: linguística, discurso forense, pragmática, dialética e argumentação. 


\section{Introducción}

El discurso forense siempre ha despertado interés, sobre todo por la repercusión que ha tenido y sigue teniendo en la sociedad. Ahora bien, este interés se ha venido acrecentando en las últimas décadas a medida que se desarrollan los estudios de la lingüística del texto, de la pragmática y el análisis del discurso. En este estudio se pretende mostrar cómo operan distintas estrategias pragmáticas y dialécticas en el discurso forense utilizadas por los abogados de la defensa y la acusación para persuadir al juez.

Se trata de una investigación de tipo empírico y de carácter etnometodológico, que supone una novedad en los estudios sobre el discurso forense oral en lengua española. A diferencia de los escasos trabajos en español sobre el discurso forense, en el ámbito anglosajón se vienen publicando trabajos sobre el comportamiento pragmático de los componentes que interactúan en los actos jurídicos orales desde mediados del siglo XIX. No obstante, en las dos últimas décadas han surgido diversos grupos de investigación para explicar el funcionamiento de los actos judiciales orales en español. Además de los fundamentos teóricos que avalan el análisis pragmático-discursivo de esta investigación, se ha tomado como base un corpus donde se recogen las conclusiones de calificación provisional y defensa en un juicio oral real. En ellas se da cuenta de las posiciones ante el hecho juzgado de cada una de las partes intervinientes: acusación, fiscal y defensa. El corpus se ha obtenido aplicando las fases de recopilación expuestas por Taranilla (2012), que consisten, de forma resumida, en la obtención, la transcripción y la anonimización del material del estudio, y las fases de análisis etnometodológico y contrastivo elaboradas y descritas en Torres $(2016,2017)$.

\section{Aspectos metodológicos en la investigación del discurso forense}

La importancia del lenguaje en el ámbito jurídico ha centrado el interés de los investigadores españoles desde la década de los noventa y, muy especialmente, en las últimas dos décadas ${ }^{4}$. Así lo demuestran, por ejemplo, estudios recientes de Ruiz (1998), Polaino y Polaino (2004), Atienza (2003, 2006a, 2013), Bernal (2010), Montolío (2012), Taranilla $(2011,2012)$ Carretero (2015), Cicres y Gavaldà (2014), Queralt (2014), Cervera y Torres (2015), Villalba (2015) y Torres $(2015,2016,2017)$. Sin embargo, y a excepción de los estudios de Taranilla $(2011,2012)$, Montolío (2012) y Torres $(2015,2016,2017)$,

4 Este tipo de estudios se sitúa en la línea de estudios descriptivos basados en la argumentación discursiva (Firacative-Ruiz, 2014) y en el análisis pragmático del lenguaje (Pedroza, 2013; García-Dussán, 2015; Ortega \& Vargas 2017). 
el corpus de estudio no suele partir de muestras reales, como sostienen López (2010) y Atienza (2013), algo que sí ocurre en el discurso jurídico anglosajón, como muestran las investigaciones de Christie (1964), Loftus y Zanni (1975), Atkinson y Drew (1978), Danet (1980), Harris (1984), Solan (1993), Quilis (1999), Tiersma (1999) y Shuy (2003).

Precisamente, Torres (2016), ha subrayado que la escasez de publicaciones sobre esta materia se debe a que en el territorio español es de aplicación lo establecido en la Ley 15/1999, del 13 de diciembre, de Protección de Datos de Carácter Personal, porque se pretende "garantizar y proteger, en lo que concierne al tratamiento de los datos personales, las libertades públicas y los derechos fundamentales de las personas físicas, y especialmente de su honor e intimidad personal y familiar" (Cortes Generales de España, 1999, p. 4). Pese a lo legítimo de su finalidad, esta disposición normativa dificulta enormemente la tarea de los investigadores al tratar de obtener un corpus de estudio basado en muestras reales, ya que la negativa 0 , incluso, el silencio de las instituciones españolas a la hora de proporcionar material de estudio se sustenta en la posible vulneración de los derechos fundamentales de los participantes de los actos judiciales ${ }^{5}$. Y no solo limita la libertad de acción y de colaboración de los profesionales del derecho, sino también la libertad de investigación de toda aquella persona interesada en esta rama del conocimiento, tal y como sostiene Del Burgo y Marchán (2000), al indicar que los primeros "temen perder el tiempo con algo [la utilización del lenguaje y los argumentos durante los actos judiciales] que consideran sabido en su elementalidad y generalidad" (p. 6). Afortunadamente, tal y como afirma Torres (2016, p. 39), en la actualidad se está produciendo un cambio de tendencia, por cuanto tanto la sociedad como las instituciones y las personas jurídicas son cada vez más conscientes de la importancia que la palabra tiene dentro del ámbito jurídico, hecho que propicia la inclusión en los planes de estudios que ofrecen las facultades de Derecho de asignaturas obligatorias centradas en la reflexión acerca de la práctica argumentativa en sede judicial o la proliferación de publicaciones y grupos de investigación nacionales interesados en el aspecto lingüístico y pragmático del discurso judicial español durante el transcurso del procedimiento judicial. Así, tras realizar una aproximación discursiva al acto judicial, adoptamos un enfoque descriptivo de carácter exploratorio para determinar cómo los abogados utilizan diferentes estrategias pragmático-discursivas en sus intervenciones producidas en la sala, tal como se recogen en el corpus de análisis.

5 Lo que se pretende decir es que hay dificultades para elaborar un corpus sobre interrogatorios en juicios orales reales por la negativa de las instituciones judiciales a proporcionarlos, aun cuando se comprometieran los solicitantes a firmar un escrito de confidencialidad y anonimización de los datos. 


\section{Caracterización del corpus utilizado}

El corpus que se toma como punto de partida en este artículo se corresponde con el caso de un delito contra la propiedad intelectual seguido por los juzgados penales de Barcelona en el año $2010^{1}$. Este acto — que se tramitó mediante el denominado procedimiento abreviado, que está previsto en los artículos 757 a 793 LECrim, y donde se solicita una pena máxima privativa de libertad de hasta nueve años con pena accesoria que suele ser de multa, pero también de inhabilitación- se inició por los motivos siguientes: el acusado, Pol Rouras Jiménez ${ }^{2}$, un joven español, estudiante de la carrera de Telecomunicaciones, creó una página web (www.thelastkeys.com) donde compartía de forma gratuita las claves de acceso a la plataforma de televisión por cable Digital Plus.

Según las comprobaciones periciales, la página estuvo activa un total de nueve meses (concretamente, desde abril hasta diciembre de 2007), tiempo durante el cual se recibieron entre 15000 y 20000 visitas mensuales, circunstancia que proporcionó al acusado unos beneficios aproximados de 270 euros, que conseguía gracias a los anuncios y al sistema de publicidad Google Ads que ofrecía en su página web. En vista de esto, los abogados identificaron al señor Rouras como acusado de los hechos. Sin embargo, la postura que defendía el fiscal era distinta de la que respaldaba la acusación particular. El primero recurrió al artículo 28 del Código Penal español para solicitar, en su escrito de conclusiones provisionales, una pena privativa de nueve meses de prisión, una multa de quince meses, a razón de 12 euros como cuota diaria y una responsabilidad personal subsidiaria de un día por cada dos cuotas impagadas y las costas judiciales. Por su parte, la postura de la acusación particular fue más severa, ya que recurrió a los artículos 66.1.3, 74.1, 123 y 286.3 y costas, según el artículo 123 del Código Penal la pena de multa de 30 meses, con una cuota diaria de diez euros, las costas judiciales y la indemnización a la prestadora del servicio con la cantidad de ciento ochenta y dos mil seiscientos noventa y siete euros (€182 697) 0 , en caso de que el juez no lo considerara oportuno, con la cantidad de dieciocho mil doscientos sesenta y tres euros $(€ 18263)^{3}$.

Frente a estas acusaciones, la parte que ejerció la defensa se limitó a solicitar la libre absolución del demandado negando todas las versiones de la historia expuestas por los abogados de la contraparte. Y lo realizó en los siguientes términos:

\footnotetext{
La transcripción completa del caso que se analiza puede encontrarse en el CD-ROM adjunto a la publicación de Taranilla (2012). Para evitar la identificación de los participantes y de la página web, se ha optado por designarlos con nombres ficticios. La diferencia entre la rigidez ambas posturas se justifica en función del tipo de abogado que solicite la pena. Si el solicitante es la acusación particular, la representación se dirige hacia la propia víctima. Si el solicitante es el fiscal, la representación recae sobre la colectividad del pueblo español.
} 
negamos los hechos que se imputan a mi defendido, [...] en cuanto a las respectivas correlativas procede la libre absolución con todos los pronunciamientos favorables y condena en costas a la acusación particular. [...] Al negar participación alguna en hecho delictivo no procede reconocimiento de delito de clase alguna. [...] Sin delito no hay autor. [...] Sin delito y sin participación no se puede hablar de circunstancias que eximan o modifiquen la responsabilidad. (Escrito de conclusiones provisionales de la defensa)

La concisión de esta exposición no responde a una falta de pruebas por parte del abogado que ejerce la defensa, sino a su decisión de no proporcionar un discurso argumentativo basado en rebatir las afirmaciones de los distintos acusadores, a fin de generar interés en el juez para que la apertura del juicio oral no llegue a ser cuestionada.

\section{Aproximación pragmadialéctica al acto judicial}

La teoría pragmadialéctica fue desarrollada en la segunda mitad del siglo XX por Van Eemeren y Grootendorst (2004). La idea básica que defiende esta teoría es que toda disputa provocada por una diferencia de opinión entre dos o más partes puede resolverse mediante una discusión argumentativa fuertemente condicionada por el lenguaje. Tal y como manifiestan estos autores (2004, p. 12), argumentar no consiste en dar importancia a los elementos extralingüísticos que acompañan a una determinada emisión verbal 0 extraverbal, sino en utilizar el lenguaje intensificando el valor perlocutivo del mismo para persuadir a un crítico razonable de un determinado razonamiento u opinión, hecho que, como hemos visto, es el que se produce.

Según los pragmadialécticos, la resolución de cualquier disputa debe discurrir por cuatro etapas o fases diferenciadas, que no necesariamente han de presentarse de forma explícita: la de confrontación (confrontation stage), la de apertura (opening stage), la argumentación (argumentation stage) y la conclusión (concluding stage).

Así pues, durante la fase de confrontación (confrontation stage) se evidencian las diferencias entre las partes implicadas en la disputa. Esta fase se inicia con la formulación de varias afirmaciones, explícitas o implícitas, que plantea una de las partes y que provoca la duda 0 el rechazo de la otra parte. En el caso de que la primera de ellas emplee afirmaciones explícitas, deben utilizarse palabras lo suficientemente sugestivas para que la parte contraria pueda oponerse o matizar lo dicho.

A continuación, tiene lugar la fase de apertura (opening stage), donde cada parte asume un papel comunicativo concreto (protagonista o antagonista), puesto que son evidentes las posturas enfrentadas. Al adquirir estos roles, cada parte manifiesta de forma 
implícita su conformidad para criticar las proposiciones de su adversario y para defender las propias en el siguiente estadio.

La etapa de la argumentación (argumentation stage) es considerada la parte principal de todo el proceso argumentativo, puesto que es el momento en que las partes exponen sus argumentos y contraargumentos para reforzar sus ideas iniciales y para desacreditar las del contrario. Esto provoca que, en ocasiones, las partes presenten nuevos argumentos que sustituyan a los que han sido invalidados o que refuercen otros argumentos anteriores. Finalmente, en la etapa de conclusiones (concluding stage) se produce la resolución de la disputa, normalmente a favor de una de las partes implicadas. Para ello, el interlocutor, cuya pretensión ha sido desestimada —o parcialmente desestimada—, debe aceptar la derrota. En caso contrario, puede iniciar una nueva discusión, lo que conlleva un reinicio de las etapas pragmadialécticas. En este sentido van dirigidas las palabras de van Eemeren y Grootendorst (2004), al decir que:

when the concluding stage has been brought to an end, the argumentative exchange of views is over, but this naturally does not mean that the same discussion partners cannot initiate a new discussion. The parties may engage in a completely different of opinion, or they may start a discussion about a more or less modified version of the old difference, possibly with different premises in the opening stage. The discussion roles of the participants may then have to change too. (pp. 61-62)

Esta afirmación encuentra razón de ser en el proceso judicial de forma evidente. Cuando la acusación remite al tribunal su escrito de conclusiones provisionales, actúa respectivamente como emisor y receptor del mensaje. En el momento en el que al acusado se le notifica que existe una posible causa penal contra su persona se convierte en receptor del mensaje. Una vez que se celebra el juicio y el juez emite la correspondiente sentencia, la parte que pierde el pleito puede recurrir el fallo. Si la parte que recurre el fallo es la acusación, los papeles comunicativos se mantendrán invariables con la única excepción del juez, que pertenece a una instancia superior. Si la parte recurrente es la defensa, los papeles comunicativos estarán invertidos, pues ejercerá como emisora de un mensaje que hará llegar a los destinatarios (los miembros del tribunal de la instancia superior y los de la acusación).

Las etapas de confrontación y apertura pragmadialécticas se corresponden con la emisión de los escritos de acusación y la correlativa de la defensa. Para ello, las partes están sujetas a lo dispuesto por el artículo 650 de la Ley de Enjuiciamiento Criminal (LECrim), donde se establece que las conclusiones de estos escritos deben ser "precisas y numeradas" y deben subordinarse a los hechos punibles resultantes del sumario, la calificación legal de los mismos hechos, con determinación expresa del delito que constituya, la participación que hubiera tenido en ellos 
el acusado 0 acusados, los hechos que constituyan circunstancias atenuantes 0 agravantes del delito y la formulación de las penas en que hayan incurrido el procesado o procesados.

El acusador privado en su caso y el Ministerio Fiscal, cuando sostenga la acción civil, expresarán, además, la cantidad en que aprecian los daños y perjuicios derivados del delito y la identificación concreta de las personas responsables de los daños y perjuicios causados.

\section{Estrategias pragmáticas de los escritos de acusación y de de- fensa}

Los estudios sobre lingüística forense basados en la exploración etnometodológica no son una novedad ${ }^{4}$. En la década de los cincuenta del siglo pasado, el sociólogo americano Harold Garfinkel (2006) realizó una serie de investigaciones relacionadas con la aplicación que del sentido común hicieron los miembros de un jurado a la hora de emitir sus deliberaciones. Se abría, así, una de las grandes vías de investigación de la lingüística forense, que prescindía del pensamiento lógico y especializado de la materia y se centraba en la descripción de la interacción jurídica en cuanto realización social de la que todos podemos formar parte, ya como participantes profesionales (o en jurado popular) 0 como participantes no profesionales, actuando como acusación o ejerciendo la defensa.

Nos encontramos, pues, ante la perspectiva que se sigue en este artículo, pues solo así se puede dar cuenta de cómo los abogados, que no solo conocen la práctica jurídica, sino que intentan, como dice Carrió (1995), influir "en la psique y la voluntad de los oyentes para hacerles cambiar de opinión, consiguiendo también que actúen de una forma determinada" (p. 60), idea remarcada asimismo por Spang (2005, p. 83). En el caso que nos ocupa, tanto las partes que ejercen la acusación como la que ejerce la defensa intentan influir en la voluntad y el ánimo del juez para que autorice la apertura del juicio oral. Para ello, las partes suelen utilizar, básicamente, dos teorías pragmáticas tradicionales: el modelo argumentativo de Toulmin y la teoría de la (des)cortesía lingüística.

\subsection{El modelo argumentativo de Toulmin}

Un argumento no puede reducirse, según Stephen Toulmin (2007, pp. 133 y ss.), a dos premisas y una conclusión, como sí ocurre en los planteamientos teóricos de carácter lógico, sino que es necesario analizarlo a la luz de seis elementos interrelacionados:

- Conclusión que debe ser probada.

- Datos o hechos empíricos concretos que apoyan dicha conclusión.

4 Hace ya casi cuatro décadas que en el ámbito anglosajón empezaron a ser conocidos los estudios de Atkinson y Drew (1978), Lynch 1982) o Maynard (1984). 
- Garantías o leyes de paso entre los datos y la conclusión.

- Elementos de respaldo que contribuyen al afianzamiento de las garantías.

- Modalizadores que matizan la conclusión que se ha hecho.

- Procedimientos de refutación que objetan esa conclusión.

Como se ha indicado, en los escritos de calificación provisional de la acusación suelen estar presentes algunos de estos elementos, puesto que, a través de los hechos o datos que se aportan, se pretende avalar una conclusión determinada. Así sucede en la solicitud de culpabilidad del acusado:

(1) Primera.- Se dirige la acusación contra Pol Rouras Jiménez, mayor de edad y cuya hoja histórico penal no consta en la presente causa, quien, en el mes de abril de 2007 registró el dominio www.thelastkeys.com y creo [sic.] la oportuna página web al efecto, página en la cual se proporcionaban las claves y códigos secretos a los visitantes de la misma (unos 15.000-20.000 al mes) para que éstos pudieran acceder a la programación de Digital + , titularidad de Grupo Sogecable, sin abonarse a dicha plataforma ni contar con su autorización, con el consiguiente perjuicio económico para la misma. En dicha página se mantenían determinados banners publicitarios, por las que, al menos, se obtuvo por el acusado una remuneración de 200-250 € al mes, mientras la página estuvo activa, esto es, hasta diciembre de 2007. (Escrito de conclusiones provisionales del Ministerio Fiscal)

En (1) el fiscal basa su acusación en tres hechos o datos que perjudican al acusado y que han supuesto un grave perjuicio a la empresa que presta el servicio. La manera de exponer estos tres hechos no es casual, pues el abogado utiliza una serie de verbos que subrayan la intencionalidad en los actos del demandado ("en el mes de abril de 2007

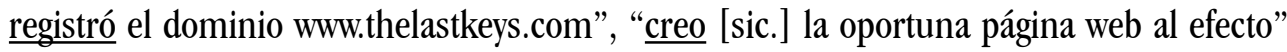
para proporcionar "las claves y códigos secretos a los visitantes de la misma"). Finalmente, se destaca que estas actuaciones redundaron en un beneficio económico para él ("se obtuvo por el acusado una remuneración de 200-250 € al mes, mientras la página estuvo activa, esto es, hasta diciembre de 2007”). Y, tras exponer las acciones que llevó a cabo el acusado, el abogado prosigue vinculando su comportamiento al incumplimiento de la Ley (o garantía, según la terminología toulminana):

(2) Segunda.- Los hechos anteriormente relatados en la conclusión primera son legalmente constitutivos de un delito contra la propiedad intelectual, previsto y penado en el artículo 270-3 del Código Penal. (Escrito de conclusiones provisionales del Ministerio Fiscal)

$5 \quad$ Las subrayas son nuestras. 
Seguidamente, se indican las conclusiones provisionales anteriores:

(3) Tercera.- Es autor el acusado, a tenor del artículo 28 del Código Penal. (Escrito de conclusiones provisionales del Ministerio Fiscal)

También se establece una vinculación entre el incumplimiento de la Ley y la sanción social que procedería imponer ${ }^{6}$, mediante la utilización de perífrasis verbales de obligación:

(4) Quinta.- Procede imponer la pena de nueve meses de prisión y multa de quince meses, a razón de $12 €$ como cuota diaria y una r.p.s. de un día por cada dos cuotas impagadas, y costas, según el artículo 123 del Código Penal.

El acusado deberá indemnizar a Grupo Sogecable en la cantidad que se determine en ejecución de sentencia, previa acreditación de los perjuicios sufridos por la actuación del acusado. (Escrito de conclusiones provisionales del Ministerio Fiscal)

El escrito de conclusión provisional de la acusación se cierra con la inclusión de elementos de respaldo que confieren más fuerza a la conclusión expresada en el punto tercero:

(5) Otrosí dice: El ministerio fiscal interesa que se aporte la hoja histórico penal del acusado, antes de proceder al envío de las presentes actuaciones al órgano de enjuiciamiento.

Otrosí dice: Asegúrense convenientemente las responsabilidades pecuniarias, formando al efecto pieza separada.

Otrosí dice: El ministerio fiscal interesa que se le dé traslado del escrito de conclusiones que en su día formule la defensa, antes de proceder al envío de la presente causa al órgano de enjuiciamiento.

Otrosí dice: Para el acto de juicio oral, este ministerio fiscal propone los siguientes medios de prueba, a fin de que por el órgano de enjuiciamiento, y de acuerdo con el artículo 785 de la Ley de Enjuiciamiento Criminal, se admitan todos ellos por entender su pertinencia:

-Interrogatorio del acusado. (Escrito de conclusiones provisionales del Ministerio Fiscal)

6 La sanción puede llegar a varias según si existen o no circunstancias atenuantes de la conducta del acusado. Esto se documenta, como norma general, en el punto cuarto de los escritos de acusación y de defensa. 
Por su parte, la correlativa de la defensa reduce drásticamente los elementos de la teoría toulminiana:

(6) Primera: A- En cuanto a la correlativa del ministerio fiscal negamos los hechos que se imputan a mi defendido.

B- En cuanto a la correlativa de la acusación particular, reiterar lo anteriormente dicho.

Segunda: A- ministerio fiscal: Al negar participación alguna en hecho delictivo no procede reconocimiento de delito de clase alguna.

B- Acusación particular: En cuanto al correlativo del apartado reiteramos todo lo mencionado en el apartado anterior en contestación al ministerio fiscal. (Escrito de la defensa)

Como se observa en (6), la defensa solo se limita a rechazar las afirmaciones de las partes que ejercen la acusación utilizando, para objetar los hechos presentados por el fiscal, una secuencia de polaridad negativa ("negamos los hechos que se imputan a mi defendido") y estableciendo una relación lógica al vincular la negación de los hechos con la inexistencia del delito ("no procede reconocimiento de delito de clase alguna"). En relación con la objeción de la narrativa de la acusación particular, la defensa utiliza el mismo razonamiento que ha empleado para refutar la narración del Ministerio fiscal, que presenta mediante el uso de un verbo reiterativo ("reiteramos todo lo mencionado en el apartado anterior en contestación al ministerio fiscal"). Tras ello, aplica un razonamiento de tipo deductivo al afirmar que sin la existencia de delito y sin la participación de su cliente "no se puede hablar de circunstancias que eximan o modifiquen la responsabilidad", como se muestra en (7) con palabras expresadas por el Ministerio Fiscal:

(7) Cuarta:

A- ministerio fiscal: Sin delito y sin participación no se puede hablar de circunstancias que eximan 0 modifiquen la responsabilidad. (Escrito de la defensa)

Y el mismo razonamiento deductivo se utiliza en la conclusión quinta, donde se presenta la inocencia del acusado, hecho que invalida las pretensiones de las partes acusadoras ("procede la libre absolución con todos los pronunciamientos favorables y condena en costas a la acusación particular" y "negar cualquier responsabilidad de mi defendido por todo lo anteriormente expuesto"), en la que se pide la libre absolución del acusado: 
(8) Quinta: A- ministerio fiscal y B-Acusación particular: en cuanto a las respectivas correlativas procede la libre absolución con todos los pronunciamientos favorables y condena en costas a la acusación particular.

Responsabilidad Civil: En cuanto a la responsabilidad civil solicitada por el ministerio fiscal y la acusación particular, negar cualquier responsabilidad de mi defendido por todo lo anteriormente expuesto. (Escrito de la defensa)

Así pues, según el modelo analítico de Toulmin, la conclusión que debe ser probada, no lo ha hecho en ningún momento la defensa y no ha aportado ningún dato comprobatorio. Antes bien, la defensa simplemente se ha limitado a negar los hechos proporcionados por la fiscalía. Y esta estrategia es la que, precisamente, permite generar expectativas en el juez para saber con qué argumentos contará la defensa durante el juicio oral para probar la falsedad de la correlativa del fiscal y de la acusación particular.

\subsection{La teoría de la (des)cortesía}

La teoría de la cortesía de Brown y Levinson (1987) constituye el presupuesto teórico sobre el que se ha basado la mayor parte de los estudios relacionados con la cortesía lingüística. Este aspecto ha sido estudiado y analizado por diversos autores, entre ellos Haverkate (1994), quien subraya la importancia de la teoría de la cortesía, al decir que

el interés por el estudio de la cortesía verbal ha ido adquiriendo proporciones espectaculares, culminando en la organización de gran cantidad de simposios y congresos internacionales, así como de la publicación de numerosos artículos y monografías dedicadas al tema. (p. 8)

Más aún, para Kerbrat-Orecchioni (1997), no se puede hablar de cortesía sin referirse a Brown y Levinson, con estas palabras: "it is imposible to talk about it [la cortesía] without referring to Brown \& Levinson's theory" (p. 11), lo que lleva a Eulen (2001) a resaltar que la teoría de Levinson es la más influyente, como sigue: "Although not the first, Brown \& Levinson's theory is certainly the most influential—witness the innumerable reactions, applications, critiques, modifications and revisions their 1978/1987 publication has triggered, and still does" (p. 3).

El hecho de que la teoría de la cortesía verbal de Brown y Levinson sea una de las que más influencia ha ejercido sobre estudios posteriores, de igual modo que ocurre con el modelo lakoffiano, estos autores analizan la cortesía en términos de conflicto. Los postulados teóricos que proponen estos autores siguen el modelo de Grice (1975), no solo por la formulación del principio de cooperación mediante las máximas de comunicación y de cortesía, sino también porque los complementa, como recuerda Escandell (1996), 
"añadiéndole la faceta interpersonal de la que carecía" (p. 148). El punto de partida de este modelo radica en la creencia de que el uso del lenguaje está regulado por una serie de principios comunicativos que rigen las relaciones interpersonales con la finalidad de salvaguardar la imagen pública de todos los interactantes sin que ello vaya en detrimento del éxito de la interacción. Los elementos que influyen en el éxito o en el fracaso comunicativo son bastante numerosos, a saber: la habilidad comunicativa de los interlocutores, su voluntad de cooperación, entre otros. Sin embargo, Brown y Levinson (1987, pp. 61-63) se interesan más por la imagen pública de los interactantes. Así, retoman el concepto goffmaniano de face para afirmar que todos los miembros adultos de una sociedad disponen de una imagen pública que desean mantener durante el acto comunicativo y que Brown y Levinson (1987) definen del siguiente modo:

Central to our model is a highly abstract notion of 'face' which consists of two specific kinds of desires ('face-wants') attributed by interactants to one another: the desire to be unimpeded in one's actions (negative face), and the desire (in some respects) to be approved of (positive face) (p. 13).

En todo acto comunicativo existe una imagen pública que debe salvaguardarse de ataques externos. Esta imagen pública, según Haverkate (1994) se bifurca en dos polos: el negativo, que proporciona cierta libertad al individuo para "actuar autónomamente" sin verse importunado por las acciones de los demás, y el positivo, que consiste en el deseo que tiene el individuo de ser apreciado por los demás miembros de la sociedad (p.19). La adscripción a uno u otro polo es evidente durante el proceso judicial, pues los abogados de la acusación (el fiscal y la acusación particular) recurren a diferentes estrategias discursivas para dañar la imagen pública del acusado 0 acusados mientras atenúan la imagen positiva de su representado. Por su parte, la representación legal de los acusados (la defensa) intenta mitigar ese daño intentando perjudicar el polo positivo de la imagen pública de la parte contraria. Veamos algunas de las estrategias utilizadas por la acusación y por la defensa:

(9) Una de esas páginas es, www.thelastkeys.com, cuyo administrador es el imputado, Pol Rouras Jiménez, pues registró el dominio y creó la página, tal como reconoció en la declaración policial y judicial. [...] En el caso que nos ocupa, tal como reconoce el imputado en su declaración judicial del 11 de febrero de 2008, reconoce haber cobrado entre 200 y 250 euros mientras la página estuvo en funcionamiento, esto es entre abril y diciembre de 2007 [...]. (Escrito de conclusiones provisionales de la Acusación Particular)

En (9) se constata que el abogado de la acusación particular identifica al acusado como autor y administrador de la página web que albergaba las contraseñas de acceso a 
la plataforma de televisión de pago ofrecida por Digital+. Esta identificación supone la proyección de una visión negativa sobre él, que se traduce en un atentado sobre el polo positivo de su imagen pública. Para ello, se basa en hechos constatables legalmente, pues alude a que el imputado "reconoce" haber creado la página web y haber registrado el dominio de la misma y haber ganado dinero mientras esta estuvo accesible al público.

Por su parte, la defensa intenta proteger el polo positivo de la imagen pública de su defendido mediante una estrategia llamativa, ya que subordina la atribución de la autoría con la existencia del delito ("no procede reconocimiento de delito de clase alguna") con una doble finalidad: mitigar el daño al polo positivo de la imagen pública del acusado y atenuar el daño contra el polo positivo de la imagen pública de la parte demandante. En consecuencia, la afirmación "sin delito no hay autor" sugiere que, si bien pudiera ser cierto que la página web existió, la parte acusadora se basa en suposiciones y versiones de los hechos que carecen de fundamento, por lo que el perjudicado es el imputado. Así se constata en la posición diferenciada de la parte de la acusación, la del Ministerio Fiscal y la de la defensa. En tales intervenciones, como se recoge en (9), la defensa pide la libre absolución de su defendido en las conclusiones $1 .^{\mathrm{a}}, 4 .^{\mathrm{a}}$ y $5 \cdot^{\mathrm{a}}$, al tiempo que rechaza la afirmación de la parte acusadora al negar cualquier responsabilidad de su defendido mediante el procedimiento deíctico endofórico ("en cuanto a la correlativa de la acusación particular, reiterar lo anteriormente dicho" mediante un plural sociativo y una expresión generalizadora ("negamos los hechos que se imputan a mi defendido" ${ }^{\prime}$ ). Por el contrario, la parte acusadora y el Ministerio Fiscal se reafirman en la responsabilidad del acusado por los hechos que se le atribuyen y en la imposición de las penas solicitadas en la $3 .^{\text {a }}$ conclusión del escrito de conclusiones provisionales.

\section{Resultados y conclusión}

A lo largo del estudio realizado se ha pretendido explicar el funcionamiento del acto judicial y de las estrategias pragmático-discursivas utilizadas por los integrantes en el escrito de conclusiones de calificación provisional y defensa, en un juicio oral real que se ha originado mediante la acción delictiva de un acusado joven.

Para centrar el análisis de los indicadores pragmático-dialécticos y discursivos, se ha recurrido a las teorías que mejor explican la interacción comunicativa para la defensa de la posición de cada parte y la refutación del contrario: la pragmadialéctica de Van Ee-

\footnotetext{
$7 \quad$ La subraya es nuestra.

$8 \quad$ La subraya es nuestra.
} 
meren y Grootendorst (2004), la etnometodología de Garfinkel (2006) la argumentativa de Toulmin (2007) y la teoría de la (des)cortesía lingüística, desarrollada por Haverkate (1994), Brown y Levinson (1987), y se han aplicado al corpus de estudio mediante un enfoque contrastivo. Este hecho ha llevado a concluir que, aunque en el escrito de conclusiones se pone de manifiesto la coincidencia de la acusación particular y la del fiscal en atribuir la responsabilidad de los hechos y la imposición de penas al acusado y la discrepancia de la defensa, que pide la libre absolución de su defendido, los abogados de cada parte recurren de modo semejante a los procedimientos de nominalización, la recurrencia léxica y gramatical y los indicadores deícticos personales en la interacción comunicativa, la tercera persona verbal, los conectores y operadores discursivos.

Así pues, entre los indicadores más visibles obtenidos del estudio lingüístico y pragmático-discursivo aplicado al corpus jurídico analizado destacan el dominio de oraciones simples y las nominalizaciones "disconforme con la correlativa del fiscal"; la recurrencia o reiteración léxica y gramatical "responsabilidad, delito, hecho, reiteramos"; la deixis anafórico-endofórica "lo mencionado, lo anteriormente expuesto" y la utilización de operadores discursivos constantes, del tipo "En cuanto a la correlativa del ministerio fiscal" 0 "en cuanto a la responsabilidad civil solicitada", para enmarcar el tema sobre el que se va a hablar. A estas estrategias se unen las derivadas de la imagen que trata de proyectar cada parte del contrario donde entra el juego de la cortesía o la descortesía, por lo que la defensa pretende en todo momento resaltar con argumentos dialécticos asertivos "sin delito no hay autor" una visión positiva de su defendido.

\section{Referencias}

Atienza, M. (2003). Tras la justicia: una introducción al derecho y al razonamiento jurídico. Barcelona: Ariel.

Atienza, M. (2006a). Diez consejos para argumentar bien o decálogo del buen argumentador. Doxa, Cuadernos de Filosofía del Derecho, (29), 473-475.

Atienza, M. (2006b). El derecho como argumentación. Barcelona: Ariel.

Atienza, M. (2013). Curso de argumentación lingüística. Madrid: Trotta.

Atkinson, J. M. \& Drew, P. (1978). Order in court. London: Macmillan.

Bernal, M. (2010). Descortesía en el contexto judicial. El caso del juicio del 11-M. En Estudios de cortesía. Coloquio del programa Edice, (pp. 599-636). Buenos Aires: Programa Edice/ Universitat de València. 
Brown, S. \& Levinson, P. (1987). Politeness: Some Universals in Language Usage. Cambridge: Cambridge University Press.

Carretero, C. (2015). La claridad y el orden en la narración del discurso jurídico. Revista de Llengua i Dret, Journal of Language and the Law, (64), 63-85.

Carrió, G. (1995). Cómo estudiar y cómo argumentar un caso. Consejos elementales para abogados jóvenes. Buenos Aires: Abeledo-Perrot.

Cervera, A. \& Torres, J. (2015). Análisis conversacional del discurso penal. Pragmalingüística, (23), 8-21.

Cicres, J. \& Gavaldà N. (2014). La lingüística forense: la llengua com a evidencia. Revista de llengua i dret, (61), 61-71.

Christie, G. C. (1964). Vagueness and Legal Language. Minnesota Law Review, (48), 885-911.

Cortes Generales de España (1978). Constitución española. Madrid: BOE. Recuperado de http:// www.boe.es/legislacion/documentos/ConstitucionCASTELLANO.pdf

Cortes Generales de España (1999). Ley Orgánica 15/1999, de 14 de diciembre, de Protección de Datos de Carácter Personal. Boletín Oficial del Estado, (298), 43088-43099. Recuperado de https://www.boe.es/boe/dias/1999/12/14/pdfs/A43088-43099.pdf

Danet, B. (1980). Language in The Legal Process. Law \& Society Review, 14(3), 445-564.

Del Burgo y Marchán, A. M. (2000). El lenguaje jurídico. Barcelona: Bosch.

Eelen, G. (2001). A Critique of Politeness Theories. Machester: Saint Jerome.

Escandell, M. V. (1996). Introducción a la pragmática. Barcelona: Ariel.

Firacative-Ruiz, R. (2014). Textualidad y gramática argumentativa. Cuadernos de Lingüística Hispánica, (24), 25-42.

García-Dussán, E. (2015). Prácticas discursivas orales, dialectos e identidad social. Cuadernos de Lingüística Hispánica, (26), 49-74.

Garfinkel, H. (2006). Estudios en etnometodología. Barcelona: Anthropos.

Grice, H.P. (1975). Lógica y conversación. En L. M. Valdés (ed.). La búsqueda del significado (pp. 511-530). Madrid: Tecnos/Universidad de Murcia.

Harris, S. (1984). Questions as Mode of Control in Magistrate's Courts. International Journal of the Sociology of Language, (49), 5-28.

Haverkate, H. (1994). La cortesía verbal: estudio pragmalingüístico. Madrid: Gredos. 
Kerbrat-Orecchioni, C. (1997). La enunciación: de la subjetividad en el lenguaje. Buenos Aires: Edicial.

Loftus, E. F. \& Zanni, G. (1975). Eyewitness Testimony: The Influence of the Wording of a Question. Bulletin of the Psychonomic Society, (5), 86-88.

López, A. (2010). Documentos profesionales con destinatarios no expertos. El empleo de los mecanismos referenciales en la sentencia del 11M. Revista Signos, 43(72), 99-123.

Lynch, M. (1982). Closure and Disclosure in Pre-trial Argument. Humanities Studies, (5), 285318.

Maynard, D. W. (1984). Inside Plea Bargaining. The Language of Negotation. New York: Plenum.

Ministerio de Gracia y Justicia de España. (1982). Real decreto de 14 de septiembre de 1882 . Ley de Enjuiciamiento Criminal. BOE, (260). Recuperado de http://www.boe.es/buscar/pdf/1882/ BOE-A-1882-6036-consolidado.pdf

Montolío, E. (ed.) (2012). Hacia la modernización del discurso jurídico: contribuciones a la I Jornada sobre la modernización del discurso jurídico español. Barcelona: Universidad de Barcelona.

Muzzopappa, J. I. (2013). Enseñanza de la gramática desde la perspectiva del enfoque generativista. Cuadernos de Lingüística Hispánica, (22), 111-126.

Ortega, F.J. \& Vargas, B.V (2017). Aproximación sociopragmática a las estrategias conversacionales de los adolescentes. Cuadernos de Lingüística Hispánica, (29), 83-103.

Pedroza, F.L. (2013). Los principios pragmáticos y la interpretación crítica del lenguaje. Cuadernos de Lingüística Hispánica, (21), 131-142.

Polaino, M. \& Polaino-Orts, M. (2004). Cometer delitos con palabras. Teoría de los actos de habla y funcionalismo jurídico-penal. Madrid: Dykinson.

Queralt, S. (2014, oct.). Atribución de autoría. Trabajando hacia un objetivo común. En III Jornadas (In)formativas de Lingüistica Forense. UAM. Facultad de Filosofía y Letras. Madrid, España.

Quilis, A. (1999). El reconocimiento de la voz en la investigación judicial. La experiencia del lingüista. En Lengua y discurso. Estudios dedicados al Profesor Vidal Lamiquiz (pp. 745751). Madrid: Arco Libros.

Ruiz, L.F. (1998). La acción como elemento del delito y la teoría de los actos de habla: cometer delitos con palabras. En Anuario de Derecho Constitucionaly Parlamentario (ADCP), LI, (pp. 5-34). Murcia: Universidad de Murcia. 
Shuy, R. W. (2003). Language Crimes. The Use and Abuse of Language Evidence in the Courtroom. Oxford: Blackwell.

Solan, L. M. (1993). The Language of the Judges. Chicago: Chicago University Press.

Spang, K. (2005). Persuasión. Fundamentos de retórica. Pamplona: Eunsa

Taranilla, R. (2011). La configuración narrativa en el proceso penal: un análisis discursivo basado en corpus. (Tesis doctoral). Barcelona: Universidad de Barcelona. Recuperado de http://www.tdx.cat/handle/10803/48717

Taranilla, R. (2012). La justicia narrante: un estudio sobre el discurso de los hechos en el proceso penal. Cizur Menor: Thomson Reuters Aranzadi.

Tiersma, P. (1999). Legal Language. Chicago: The University of Chicago Press.

Torres, J. (2015, marzo). Poder, solidaridad y (des)cortesía: el papel del juez y el juicio oral. In $I V$ Jornadas de Iniciación a la Investigación. UCM, Filología. Madrid, España.

Torres, J. (2016). Los discursos jurídicos: análisis pragmagramatical del español. Madrid: Universidad Complutense de Madrid.

Torres, J. (2017). Lingüistica procesal: estrategias discursivas en los juicios españoles. Vallirana: Librería Bosch.

Toulmin, S. (2007). Los usos de la argumentación. Barcelona: Península.

Van Eemeren, F. H. \& Grootendorst, R. (2004). A Systematic Theory of Argumentation: The Pragma-Dialectical Approach. New York: Cambridge University Press.

Villalba, C. (2015). La ficha ES.VAR.ATENUACIÓN. ¿Un recurso adaptable a todos los géneros? El caso de los juicios orales. Textos en Proceso, 1(2), 1-24. 